\title{
Viral factors and outcome of chronic hepatitis B revisited
}

\author{
François Habersetzer • Rémy Moenne-Loccoz • \\ Thomas F. Baumert
}

Received: 2 July 2013/Accepted: 20 August 2013/Published online: 11 September 2013

(C) Asian Pacific Association for the Study of the Liver 2013

Virus-host interactions during chronic hepatitis $\mathrm{B}$ virus (HBV) infection allow the distinction of several phases, defined according to virological, biochemical and histological profiles: immune-tolerant (IT) [HBeAg-positive, very high serum level of HBV DNA, normal serum alanine aminotransferase (ALT) level without significant liver necroinflammation activity and fibrosis], immune-reactive (HBeAg-positive, high HBV DNA and ALT levels with moderate to severe liver activity and fibrosis) and the inactive carrier state, which follows $\mathrm{HBeAg}$ seroconversion and reflects host immune control of the HBV infection (HBeAg-negative, low HBV DNA level, normal ALT level without liver damage in most cases). An HBeAg-negative chronic hepatitis B (CHB) phase (HBeAg-negative, HBV DNA level above 2,000-20,000 IU/mL, normal/high ALT level and histological signs of CHB) occurs in patients who have achieved $\mathrm{HBeAg}$ seroconversion or in inactive carriers due to $\mathrm{HBV}$ reactivation [1]. Basal core promoter

This is an editorial to the article available at doi:10.1007/s12072-0139438-z

F. Habersetzer $(\square) \cdot$ R. Moenne-Loccoz · T. F. Baumert $(\square)$ Service d'Hépatogastroentérologie, Hôpitaux Universitaires de Strasbourg, Nouvel Hôpital Civil, 1 Place de l'Hôpital, 67091 Strasbourg, France

e-mail: francois.habersetzer@chru-strasbourg.fr

T. F. Baumert

e-mail: Thomas.Baumert@unistra.fr

R. Moenne-Loccoz

e-mail: remy.moenne-loccoz@chru-strasbourg.fr

F. Habersetzer - T. F. Baumert

Inserm U1110, 3 Rue Koeberlé, 67000 Strasbourg, France

F. Habersetzer · T. F. Baumert

Université de Strasbourg, 67000 Strasbourg, France
(BCP) mutations have been reported to possibly modulate HBV replication [2-4] and could thus impact the natural course of CHB. In addition, BCP mutations (the more common are the BCP A1762T/G1764A dual mutations) and precore G1896A mutation lead to the impairment and abolishment, respectively, of HBeAg production [5], and they have been reported in patients with $\mathrm{HBeAg}$-negative CHB occurring under immune pressure to control HBV infection. Importantly, the more common BCP dual mutations have been shown to increase the risk of developing hepatocellular carcinoma (HCC) $[6,7]$.

Turyadi et al. [8] carried out a cross-sectional study to characterize the relationships between viral factors and the natural history of CHB within the Indonesian population. In their study, Turyadi et al. assessed the correlations between viral parameters [serum $\mathrm{HBs} A g, \mathrm{HBeAg}$ and $\mathrm{HBV}$ DNA levels, HBV genotype and BCP (A1762T/G1764A)/ precore (G1896A) mutations] in different stages of HBV infection within a cohort of 152 treatment-naive Indonesian patients. Patients were categorized into the four phases of CHB, denoted IT, immune-clearance (IC, i.e, immunereactive phase), low/non-replicative (LR, i.e., inactive carrier state) and HBeAg-negative CHB (ENH). The authors showed that HBsAg and HBV DNA serum levels were both at a high level and strongly correlated in the early phases of CHB (i.e., IT and IC), but a tendency to separate from one another occurred after $\mathrm{HBeAg}$ seroconversion. A moderate correlation between serum HBV DNA and serum HBsAg titers was found in the ENH phase, and no correlation was observed in the LR phase. These important results are consistent with previous studies $[9,10]$ and suggest that the control of HBV replication by the immune system does not hamper HBsAg production. In this study, a temporal relationship between $\mathrm{HBeAg}$ seroconversion and an increase of prevalence of patients with 
Table 1 HBV viral parameters and frequencies of BCP/precore mutations in the different phases of CHB in 152 Indonesian patients

\begin{tabular}{|c|c|c|c|c|}
\hline & \multicolumn{4}{|l|}{$n=152$} \\
\hline & \multicolumn{2}{|l|}{$\mathrm{HBeAg}$ positive } & \multicolumn{2}{|l|}{$\mathrm{HBeAg}$ negative } \\
\hline & IT phase $(n=33)$ & IC phase $(n=32)$ & LR phase $(n=34)$ & ENH phase $(n=53)$ \\
\hline HBsAg level $\left(\log _{10} \mathrm{IU} / \mathrm{mL}\right)$ & +++ & +++ & ++ & +++ \\
\hline HBV DNA level $\left(\log _{10} \mathrm{IU} / \mathrm{mL}\right)$ & +++ & +++ & + & +++ \\
\hline HBeAg level (PEIU/mL) & ++ & ++ & N/A & N/A \\
\hline Frequency $(\%)$ of BCP mutations: A1762T/G1764A & ++ & ++ & ++ & ++ \\
\hline Frequency (\%) of precore mutation: G1896A & - & + & ++ & ++ \\
\hline
\end{tabular}

High, moderate, low or absence of different HBV viral parameters are represented by,,++++++ or - , respectively

$B C P$ basal core promoter, $C H B$ chronic hepatitis B, ENH HBeAg-negative CHB, IC immune-clearance, $I T$ immune-tolerant, $L R$ low/nonreplicative, $N / A$ not applicable

$\mathrm{BCP} /$ precore mutations was shown, suggesting that the immune control that occurs during $\mathrm{CHB}$ is instrumental in selecting variants defective for $\mathrm{HBeAg}$ production. As it was found that BCP mutations were similarly distributed among the CHB phases [8], immune pressures could occur at any $\mathrm{CHB}$ stage and select virions with BCP mutations. Turyadi et al. did not find a correlation between HBV DNA and $\mathrm{HBeAg}$ levels in the IT and IC phases. This may be accounted for by the impairment of HBeAg production in part caused by $\mathrm{BCP} /$ precore mutants, which this study already found in the early stages of $\mathrm{CHB}$. Levels of the main viral factors and frequencies of $\mathrm{BCP} /$ precore mutations assessed in this study are summarized in Table 1.

As the authors have outlined, this study has several limitations. The number of patients was small, and virological and biochemical parameters, used to classify the patients according to $\mathrm{CHB}$ phases, were measured only once. However, during the course of CHB, HBV DNA and ALT levels spontaneously fluctuate, particularly in the ENH phase [11]. Thus, some patients may have been misclassified. Moreover, according to the criteria used to determine the disease stage [8], the group of patients in the LR phase possibly included both inactive carriers and patients with active ENH. Indeed, even if inactive carriers may have HBV DNA levels up to 20,000 IU/mL, ALT levels should remain normal [1]. Histological parameters are key to the proper assessment of hepatitis activity and liver fibrosis. In this study, none of the patients underwent a liver biopsy (LB), which might have increased the risk of misclassification [12]. In addition, the lack of LB precluded correlation of the CHB stage with intrahepatic viral parameters, such as covalently closed circular DNA (cccDNA). Finally, patients coinfected with human immunodeficiency virus or hepatitis D virus, which can modulate the course of HBV infection [1], were not excluded from this study.

Aiming to address the role of viral factors in HBV pathogenesis, Turyadi et al.'s [8] study provides an interesting and extensive characterization of associations between the main viral factors in the different stages of the natural course of CHB within an Indonesian cohort. This is a unique study involving the analysis of correlations between major $\mathrm{HBV}$ viral factors in the four phases of $\mathrm{CHB}$ and in a cohort of Indonesian patients (Table 1). Indeed, such a study has not been performed so far in this ethnic group. Interestingly, this work confirmed the results that previous studies partially addressed. Importantly, a key finding of this study is that BCP mutations were found in comparable distribution among the different $\mathrm{CHB}$ phases [8]. Since it was previously shown in different ethnic groups that BCP mutations increase the risk of developing HCC $[6,7]$, Turyadi et al.'s results reinforce the importance of performing further clinical studies with the aim to seek BCP mutations in chronically HBV-infected patients, regardless of the stage of disease, in order to determine their impact on HCC development and their usefulness in routine clinical practice.

In conclusion, in the setting of the HBV clinical cohort studies performed, most of them comprise patients with Chinese, Taiwanese and/or Korean origin (living in areas where $\mathrm{HBV}$ is strongly endemic); this study gives an extensive and unique overview of associations between major viral factors occurring during the natural course of $\mathrm{CHB}$ within an Indonesian population. Evaluation of $\mathrm{HBV}$ viral markers in different chronically $\mathrm{HBV}$-infected populations is crucial in order to determine whether the viral correlations during the course of HBV infection are modulated by the ethnic-related background.

Conflict of interest François Habersetzer, Rémy Moenne-Loccoz, and Thomas F. Baumert report no conflicts of interest.

\section{References}

1. European Association for the study of the liver. EASL clinical practice guidelines: management of chronic hepatitis B virus infection. J Hepatol. 2012;57:167-185 
2. Baumert TF, Rogers SA, Hasegawa K, Liang TJ. Two core promotor mutations identified in a hepatitis B virus strain associated with fulminant hepatitis result in enhanced viral replication. J Clin Invest. 1996;98:2268-2276

3. Baumert TF, Marrone A, Vergalla J, Liang TJ. Naturally occurring mutations define a novel function of the hepatitis B virus core promoter in core protein expression. J Virol. 1998;72: 6785-6795

4. Baumert TF, Yang C, Schürmann P, Köck J, Ziegler C, Grüllich $\mathrm{C}$, et al. Hepatitis B virus mutations associated with fulminant hepatitis induce apoptosis in primary Tupaia hepatocytes. Hepatology. 2005;41:247-256

5. Chotiyaputta W, Lok ASF. Hepatitis B virus variants. Nat Rev Gastroenterol Hepatol. 2009;6:453-462

6. Baptista M, Kramvis A, Kew MC. High prevalence of 1762(T) 1764(A) mutations in the basic core promoter of hepatitis B virus isolated from black Africans with hepatocellular carcinoma compared with asymptomatic carriers. Hepatology. 1999;29:946-953

7. Kao JH, Chen PJ, Lai MY, Chen DS. Basal core promoter mutations of hepatitis B virus increase the risk of hepatocellular carcinoma in hepatitis B carriers. Gastroenterology. 2003;124: $327-334$
8. Turyadi, Thedja MD, Ie SI, Harahap AR, El-Khobar KE, Roni M, et al. (2013) HBsAg, HBeAg and HBV DNA level changes and precore/basal core promoter mutations in the natural history of chronic hepatitis B in Indonesian patients. Hepatol Int. doi:10. 1007/s12072-013-9438-z

9. Thompson AJV, Nguyen T, Iser D, Ayres A, Jackson K, Littlejohn M, et al. Serum hepatitis B surface antigen and hepatitis B e antigen titers: disease phase influences correlation with viral load and intrahepatic hepatitis B virus markers. Hepatology. 2010; 51:1933-1944

10. Nguyen T, Thompson AJV, Bowden S, Croagh C, Bell S, Desmond PV, et al. Hepatitis B surface antigen levels during the natural history of chronic hepatitis B: a perspective on Asia. J Hepatol. 2010;52:508-513

11. Brunetto MR, Oliveri F, Coco B, Leandro G, Colombatto P, Gorin JM, et al. Outcome of anti-HBe positive chronic hepatitis B in alpha-interferon treated and untreated patients: a long term cohort study. J Hepatol. 2002;36:263-270

12. Villa E, Fattovich G, Mauro A, Pasino M. Natural history of chronic HBV infection: special emphasis on the prognostic implications of the inactive carrier state versus chronic hepatitis. Dig Liver Dis. 2011;43(Suppl 1):S8-14 